\title{
O069: Efficacy of cleaning methods post- inoculation of pathogenic microorganisms of conventional and novel cleankeys computer keyboards
}

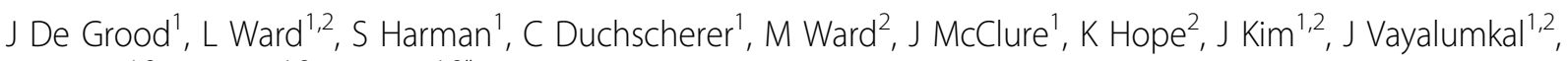 \\ K Zhang ${ }^{1,2}$, T Louie L $^{1,2}$, J Conly , $^{1 *}$
}

From 2nd International Conference on Prevention and Infection Control (ICPIC 2013)

Geneva, Switzerland. 25-28 June 2013

\section{Introduction}

Keyboards (KB) may play a role in the spread of healthcare pathogens (HCP). A survey in our hospitals revealed $58.3 \%(134 / 230)$ were + for at least $1 \mathrm{HCP}$ with $60.9 \%$ contaminated with fecal organisms.

\section{Objectives}

We sought to determine the adequacy of cleaning methods of conventional and novel acrylic and glass Cleankeys KBs, an innovative, wireless, waterproof KB.

\section{Methods}

Ten conventional and 12 Cleankeys KBs were inoculated with methicillin-resistant S.aureus (MRSA),vancomycinresistant Enterococcus (VRE), P.aeruginosa (PA) and $C$. difficile $(\mathrm{CD})$ using a modified technique described by Rutala. Every 2nd key was inoculated with $5 \times 10^{3} / 50$ ul of each organism. Cleaning using a standardized protocol was done with CaviWipes ${ }^{\mathrm{TM}}(0.28 \%$ quaternary ammonium and $17.2 \%$ isopropanol), PCS 1000 Bleach Wipes and Microfibre cloths and dish soap/water. Cultures were obtained with a standardized method using sterile applicators moistened with 0.01M PBS. The applicators were transferred into tubes containing TSB, vortexed, and planted on selective media.

\section{Results}

CaviWipes ${ }^{\mathrm{TM}}$ were effective at eliminating MRSA, VRE and PA (97\%) from all 3 types of KBs but were ineffective at eliminating CD with $100 \%$ of keyboards remaining CD +. PCS 1000 Bleach Wipes and Microfiber cloths eliminated MRSA, VRE and PA from all KB tested, were ineffective for conventional KBs with $100 \%$ remaining culture $\mathrm{CD}+$ but eliminated $\mathrm{CD}$ from both acrylic and glass Cleankeys KBs. Plain dish soap and water were $100 \%$ effective at eliminating CD from both acrylic and glass Cleankeys KBs. Conventional keyboards could not be immersed in water.

\section{Conclusion}

KBs represent a high-touch surface for colonization with HCPs. The efficacy of conventional cleaning agents may be suboptimal for conventional KBs harboring CD. An innovative keyboard, washable in plain soap and water offers distinct advantages in promoting hospital hygiene.

\section{Disclosure of interest}

None declared.

\section{Author details}

${ }^{1}$ University of Calgary, Canada. ${ }^{2}$ Alberta Health Services, Calgary, Canada.

Published: 20 June 2013

doi:10.1186/2047-2994-2-S1-069

Cite this article as: De Grood et al:: O069: Efficacy of cleaning methods post-inoculation of pathogenic microorganisms of conventional and novel cleankeys computer keyboards. Antimicrobial Resistance and Infection Control 2013 2(Suppl 1):O69.

'University of Calgary, Canada

Full list of author information is available at the end of the article

(c) 2013 De Grood et al; licensee BioMed Central Ltd. This is an Open Access article distributed under the terms of the Creative 